\title{
RACIOCÍNIO PROPORCIONAL EM UMA ATIVIDADE DE MODELAGEM MATEMÁTICA POR ALUNOS DA EDUCAÇÃO INFANTIL
}

\author{
PROPORTIONAL REASONING IN A MATHEMATICAL MODELLING \\ ACTIVITY BY CHILDREN IN CHILDHOOD EDUCATION
}

\author{
LETÍCIA COUTINHO 1 \\ EMERSON TORTOLA ${ }^{2}$
}

\section{RESUMO}

Com o objetivo investigar como alunos da Educação Infantil mobilizam o raciocínio proporcional em uma atividade de modelagem matemática, analisamos uma atividade de modelagem matemática desenvolvida com 17 alunos de uma turma de maternal III, de 3 e 4 anos, em um Centro Municipal de Educação Infantil, público, localizado no Centro Ocidental Paranaense. Os dados foram coletados por meio de gravações em áudio, vídeo, registros fotográficos, anotações em diário de campo dos pesquisadores e produções escritas dos alunos. Os dados foram submetidos à uma análise qualitativa a partir da qual sinalizamos os indícios de mobilização do raciocínio proporcional, com base nos sete aspectos caracterizados por Lamon (2012). Os encaminhamentos dos alunos para a atividade de modelagem matemática indicam que ao interpretar a situação-problema, eles identificaram grandezas, observaram seus comportamentos e inferiram relações entre elas, mobilizando os aspectos: quantidades e covariação, raciocínio relativo, partilha e comparação, unitização e medição.

Palavras-chave: Educação Matemática. Modelagem Matemática. Raciocínio Proporcional. Educação Infantil. Sala de Aula.

\section{ABSTRACT}

In order to investigate how children in Childhood Education mobilize the proportional reasoning in a mathematical modelling activity, we analyzed a mathematical modelling activity developed with 17 students of a maternal class, aged 3 and 4 years old, at a Municipal Early Childhood Education Center, public, located in the Western Center of Paraná. The data were collected through audio recordings, video, photographic records, notes in the researchers' field diary and productions written by the students. The data were analyzed in a qualitative analysis based on the proportional reasoning mobilization indicators, based on the seven aspects characterized by Lamon (2012). The students' referrals to the mathematical modeling activity show that, when they interpreted a problematic situation, they identified variables, observed their trends and inferred the relationships between them, mobilizing the aspects: quantities and covariation, relative thinking, sharing and comparing, unitizing and measurement.

Keywords: Mathematics Education. Mathematical Modelling. Proportional Reasoning. Early Childhood Education. Classroom.

\section{RESUMEN}

Con el fin de investigar cómo los estudiantes de Educación Infantil movilizan el razonamiento proporcional en una actividad de modelación matemática, analizamos una actividad de modelación matemática desarrollada con 17 estudiantes de una clase de jardín de infantes, de 3 y 4 años, en un Centro Municipal de Educación Infantil, público, ubicado en el

1 Mestra em Ensino de Matemática. Universidade Tecnológica Federal do Paraná. E-mail: let_coutinho@hotmail.com. Orcid: https://orcid.org/ 0000-0001-5134-571X.

2 Doutor em Ensino de Ciências e Educação Matemática. Universidade Tecnológica Federal do Paraná. E-mail: emersontortola@utfpr.edu.br. Orcid: https://orcid.org/0000-0002-6716-3635. 
centro occidental de Paraná. Los datos fueron recolectados a través de grabaciones de audio y video, registros fotográficos, notas en los diarios de campo de los investigadores y producciones escritas de los estudiantes. Los datos se sometieron a un análisis cualitativo a partir del cual señalamos la evidencia de la movilización del razonamiento proporcional, basado en los siete aspectos caracterizados por Lamon (2012). Las referencias de los estudiantes a la actividad de modelación matemática indican que al interpretar la situación del problema, ellos identificaron variables, observaron sus comportamientos e infirieron relaciones entre ellos, movilizando los aspectos: cantidades y covariación, razonamiento relativo, compartiendo y comparación, unitización y medición.

Palabras-clave: Educación Matemática. Modelación Matemática. Razonamiento Proporcional. Educación Infantil. Salón de Clases.

\section{INTRODUÇÃO}

As práticas pedagógicas da Educação Infantil devem contemplar por meio de brincadeiras e atividades lúdicas questões associadas às experiências das crianças. Elas devem ser colocadas diante de situações sobre as quais elas têm condições de pensar, discutir, refletir e opinar, valorizando os conhecimentos adquiridos a partir de suas vivências fora da escola.

Para isso o professor precisa (re)conhecer as crianças como alunos que, embora jovens, são histórica e socialmente constituídos - ou melhor dizendo, em constituição -, e não exclusivamente por conhecimentos elencados em um currículo.

Dessa forma, a prática do professor da Educação Infantil deve se inspirar em atitudes que visam a problematização e a investigação de situações associadas ou provenientes de suas vivências. Atividades de modelagem matemática podem ser uma alternativa pertinente à tal prática, condizentes com essas atitudes.

De acordo com Almeida, Silva e Vertuan (2012), Modelagem Matemática é uma alternativa pedagógica que visa abordar por meio da Matemática, situações não essencialmente matemáticas. Nesse sentido, "coloca o aluno frente a situações autênticas que ele presencia, ou pode vir a presenciar em sua vida, e o leva a interpretá-las com o auxílio da matemática” (TORTOLA; ALMEIDA, 2016, p. 85).

Atividades de Modelagem Matemática, portanto, vão para além da resolução de problemas, "são atividades reveladoras do pensamento que exigem que as próprias crianças desenvolvam interpretações matemáticas das situações" (FOX, 2006, p. 225). Elas valorizam as experiências e os conhecimentos dos alunos e, dessa maneira, eles têm a oportunidade de dar sentido às situações estudadas e têm condições de matematizá-las. Além disso, o uso de contextos do mundo real pode instigar os alunos a se interessar pela matemática e a utilizá-la para dar sentido ao mundo físico e social (FOX, 2006), já que problemas exteriores à sala de aula nem sempre estão completos e bem definidos, havendo a necessidade de buscar mais informações para compreendê-Ios (TORTOLA; ALMEIDA, 2016).

Tendo em vista que a Modelagem Matemática prioriza situações de acordo com as vivências dos alunos e os encorajam não só a fornecer uma resposta, mas também a explicar seu raciocínio (FOX, 2006), consideramos que a Educação Infantil é um momento oportuno para abordar as primeiras noções que servirão como base para a construção do conhecimento matemático, especificamente de raciocínios que devem ser desenvolvidos ao longo da vida escolar do aluno e que constituirão sua maneira de ver o mundo e de pensar matematicamente.

Um desses raciocínios é o raciocínio proporcional, "utilizado para descrever conceitos e pensamentos requeridos para a compreensão de taxas, razões e proporções" (NORTON, 2005, p. 17). 
Está associado à "consideração de um número em termos relativos, ao invés de termos absolutos" (ONTARI0, 2012, p. 3) e está intimamente ligado ao estabelecimento de relações de natureza multiplicativa (NORTON, 2005) e, portanto, é necessário para o entendimento de porcentagens, taxas de variação, trigonometria, álgebra e outras vertentes da matemática.

0 conceito de raciocínio proporcional vai além da mecanização de estratégias formais de resolução de problemas, está associado à capacidade de analisar, de forma consciente, as relações entre quantidades, evidenciada por argumentos e explicações sobre as relações proporcionais (COSTA; PONTE, 2008, p. 66).

Com base nas considerações de Costa e Ponte (2008), acreditamos que 0 desenvolvimento do raciocínio proporcional, particularmente na Educação Infantil, deve partir do princípio de valorizar as estratégias utilizadas pelos alunos na resolução de problemas, uma vez que, de acordo com os autores, eles já conseguem resolver situações-problema que envolvem relações proporcionais no seu dia-a-dia, antes mesmo do ensino formal, recorrendo a estratégias intuitivas, de caráter informal, ainda que geralmente aditivas. Caso contrário, eles tendem a utilizar estratégias formais ensinadas na escola, porém, muitas vezes sem compreender o que estão fazendo, o que pode acarretar 0 uso de regras e mecanismos sem necessidade, descreditando seu conhecimento intuitivo.

"Embora o Raciocínio Proporcional possa ser desenvolvido antes e fora da escola, é nela que os conhecimentos iniciais e espontâneos se tornam sistematizados e mais efetivos" (SPINILLO, 1994, p. 113). Dessa forma, os professores da Educação Infantil devem estar preparados para formalizar noções que as crianças trazem de seu cotidiano e para propiciar a construção de novos conhecimentos, preparando os alunos para futuras formalizações. Isso pode se dar por meio de jogos, brincadeiras e outras atividades lúdicas baseadas em experiências dos alunos.

Consideramos, portanto, que atividades de Modelagem Matemática podem ser utilizadas para auxiliar no desenvolvimento do Raciocínio Proporcional, uma vez que primam pela problematização e investigação de situações associadas às experiências dos alunos, além deles serem encorajados a desenvolver uma gama de estratégias de resolução de problemas e a refletir sobre suas próprias ideias (FOX, 2006).

Nesse contexto, nossa pesquisa tem como objetivo investigar como alunos da Educação Infantil mobilizam o raciocínio proporcional em uma atividade de modelagem matemática?

Para isso analisamos uma atividade de modelagem matemática desenvolvida com 17 alunos de uma turma de maternal III, com 3 e 4 anos, em um Centro Municipal de Educação Infantil, público, localizado no Centro Ocidental Paranaense. Os dados foram coletados por meio de gravações em áudio, vídeo, registros fotográficos, anotações em diário de campo dos pesquisadores e produções escritas dos alunos.

Os resultados que apresentamos integram a pesquisa de mestrado da primeira autora, orientada pelo segundo autor, desenvolvida no âmbito do Programa de Pós-Graduação em Ensino de Matemática (PPGMAT) da Universidade Tecnológica Federal do Paraná (COUTINHO, 2020). Um ensaio dessa investigação foi publicado no XV Encontro Paranaense de Educação Matemática (EPREM) em Coutinho e Tortola (2019).

\section{MODELAGEM MATEMÁTICA}

Na literatura nos deparamos com vários entendimentos de Modelagem Matemática e em relação ao seu uso no contexto educacional. Esses entendimentos refletem os olhares de cada pesquisador, 
que vêm revestidos de suas experiências, interesses e concepções, e contribuem para a compreensão do que chamamos Modelagem Matemática na perspectiva da Educação Matemática. Para o presente estudo nos fundamentamos no entendimento de Almeida, Silva e Vertuan (2012) que propõem a Modelagem Matemática como uma alternativa pedagógica às práticas escolares, que engloba a investigação de uma situação-problema não essencialmente matemática, na qual os alunos buscam na matemática subsídios para solucionar um problema definido.

Almeida, Silva e Vertuan (2012) explicam que a Modelagem Matemática, ou abreviadamente Modelagem, está relacionada com um "modo", uma "maneira" de trabalhar com atividades em aulas de matemática. Tem a intencionalidade de envolver os alunos com situações autênticas que eles tenham presenciado ou possam vir a presenciar em sua vida (TORTOLA; ALMEIDA, 2016).

As discussões sobre modelagem, no âmbito da Educação Matemática, contemplam reflexões acerca do ensino de matemática, em defesa de uma alternativa pedagógica que oportunize aos educadores criar oportunidades de aprendizagem, potencializando habilidades que esperamos que os alunos venham a desenvolver, como resolver problemas e raciocinar matematicamente (ENGLISH, 2006; FOX, 2006; BRASIL, 2018).

Considerando que habilidades expressam aprendizagens que devem ser asseguradas aos alunos nos diferentes contextos escolares (BRASIL, 2018), pensamos que os educadores, desde os primeiros anos escolares, precisam alinhar atividades de modelagem matemática às atividades que desenvolvem habitualmente em sua prática de sala de aula, uma vez que, de acordo com Fox (2006, p. 223), atividades de modelagem matemática "são atividades reveladoras do pensamento, que exigem que as próprias crianças desenvolvam interpretações matemáticas das situações".

Essas interpretações envolvem a análise de uma situação-problema e 0 uso de procedimentos e conceitos matemáticos, que são acionados com a finalidade de determinar para a problemática uma solução. Almeida, Silva e Vertuan (2012) descrevem esse delineamento como a síntese de uma atividade de modelagem matemática, cuja problemática a ser estudada consiste na situação inicial, e a solução do problema, geralmente apresentada a partir da produção de um modelo matemático, na situação final.

Modelo matemático é um sistema conceitual, descritivo ou explicativo, expresso por meio de uma linguagem ou uma estrutura matemática e que tem por finalidade descrever ou explicar o comportamento de outro sistema, podendo mesmo permitir a realização de previsões sobre este outro sistema. Um modelo matemático é, portanto, uma representação simplificada da realidade sob a ótica daqueles que a investigam. Sua formulação, todavia, não tem um fim em si só, mas visa fomentar a solução de algum problema (ALMEIDA; SILVA; VERTUAN, 2012, p. 13).

Os procedimentos e conceitos que orientam a passagem da situação inicial à situação final são descritos pelos autores em quatro fases: inteiração; matematização; resolução; e interpretação de resultados e validação.

A inteiração é a fase em que os alunos se familiarizam com o tema a ser estudado; buscam conhecer características e especificidades da situação. Nessa fase, os alunos cercam-se de informações que são obtidas por meio de coleta de dados qualitativos e quantitativos, seja por contato direto ou indireto. "A inteiração conduz a formulação do problema e a definição de metas para sua resolução" (ALMEIDA; SILVA; VERTUAN, 2012, p. 15). Essa formulação está relacionada a algo que se pretende investigar, ao mesmo tempo em que requer que alguns aspectos sejam conhecidos. 
E mesmo que seja uma fase inicial, ela pode se estender durante toda a atividade, uma vez que novas informações podem ser necessárias.

A matematização está relacionada ao momento em que a matemática é acionada para auxiliar na interpretação e na resolução da situação-problema, ou seja, a situação que inicialmente é discutida em termos de uma linguagem natural, sob o ponto de vista do fenômeno, agora é descrita e analisada com 0 auxílio da linguagem matemática. Nessa transição de linguagens as descrições e análises matemáticas são realizadas por meio da identificação e seleção de variáveis, formulação de hipóteses e realização de simplificações (ALMEIDA; SILVA; VERTUAN, 2012).

A resolução, por sua vez, refere-se à busca por uma solução ao problema sob investigação, que geralmente se dá por meio da construção de um modelo matemático, que permite descrever a situação, analisar matematicamente aspectos importantes em relação ao problema e fornecer uma resposta. Além disso, o modelo matemático elaborado também pode ser útil em realizar previsões acerca do problema em estudo.

E, por fim, a fase interpretação de resultados e validação, consiste na análise, interpretação e verificação do modelo matemático e de seus resultados. Permite dizer se o modelo obtido é adequado e condizente com a situação estudada. Nessa fase, o objetivo não é olhar isoladamente para a resolução matemática associada ao problema, mas sim considerá-la tanto em relação aos procedimentos empreendidos, quanto à sua adequação para a situação (ALMEIDA; SILVA; VERTUAN, 2012).

Essas fases não precisam acontecer necessariamente na ordem apresentada, pois segundo Almeida, Silva e Vertuan (2012) elas podem ser revisitadas a qualquer momento durante o desenvolvimento da atividade, conforme as necessidades que se apresentar.

Além das quatro fases, Fox (2006) acrescenta a importância de uma plenária em que os alunos apresentam aos seus colegas os modelos que criaram, momento que oferece oportunidades para desenvolver a linguagem oral, sua expressividade, a comunicação de ideias, observar e refletir sobre as diferentes opiniões apresentadas, gerando questionamentos, diálogo e favorecendo o desenvolvimento do senso crítico.

\section{MODELAGEM MATEMÁTICA NA EDUCAÇÃO INFANTIL}

As discussões em relação à Modelagem Matemática no âmbito da Educação Infantil são recentes, por isso ainda são poucas as pesquisas divulgadas na literatura que abordam a temática (MACHAD0, 2009). Silva e Klüber (2012) por meio de uma pesquisa bibliográfica pelo Banco de Teses e Dissertações da Capes sobre quais níveis de ensino estão focadas as pesquisas brasileiras sobre Modelagem Matemática na Educação Matemática, constataram uma precariedade de pesquisas na Educação Infantil. Dentre as 85 dissertações encontradas nenhuma delas tinha como foco a Educação Infantil. Infelizmente, esse quadro mudou muito pouco, apenas três dissertações foram produzidas com esse foco desde então (SILVA, 2013; COUTINHO, 2020; ZAMPIROLLI, 2020).

Silva e Klüber (2012) destacam também que na prática de sala de aula falta a aproximação do ensino de matemática com o que a criança vivencia em seu cotidiano, ou seja, nos preocupamos em demasiado com os conteúdos e os conhecimentos que a criança traz de suas experiências cotidianas acabam ignorados. Nos primeiros anos escolares "é preciso contribuir com o desenvolvimento integral da criança e, em especial, oferecer subsídios para o exercício da cidadania" (SILVA; KLÜBER, 2012, p. 230), ou seja, não faz sentido pensar em uma formação matemática que ignore os conhecimentos trazidos de onde se espera que os conhecimentos sejam empregados. 
Com relação ao uso da Modelagem Matemática na Educação Infantil, Silva (2013) relata 0 estranhamento de alguns colegas ao direcionar sua pesquisa de mestrado nesse contexto. Segundo a autora, esse estranhamento está relacionado com a concepção de que a Modelagem na Educação Matemática está mais voltada a alunos de graduação, ou adultos, e não a crianças. A autora revelou, porém, que a partir de questionamentos realizados por ela as crianças foram incentivadas a falar e, por meio das ideias levantadas, se apropriaram de conceitos que não conheciam ou que, muitas vezes, passavam despercebidos.

Diante desse cenário da Modelagem Matemática, alguns pesquisadores têm se dedicado a investigá-la nos primeiros anos escolares, tanto em âmbito nacional, quanto internacional (ENGLISH, 2006; 2009; FOX, 2006; TORTOLA, 2012; 2016), pelo fato de acreditar que as crianças já possuem condições de resolver problemas à sua maneira, utilizando conhecimentos condizentes com sua idade e série escolar.

Fox (2006) apresentou justificativas para desenvolver atividades de Modelagem Matemática desde a primeira infância, baseadas em orientações, documentos curriculares e recomendações feitas pelo Conselho Nacional de Professores de Matemática (NCTM) e Associação Nacional para a Educação de Crianças Pequenas (NAEYC). Como uma das orientações discutidas pela autora é incentivar e aprimorar 0 interesse natural das crianças pela matemática e sua disposição de usá-la para dar sentido ao seu mundo físico e social, acredita-se que a Modelagem Matemática é uma alternativa que atende a essa orientação, uma vez que valoriza os conhecimentos das crianças, os encaminhamentos e estratégias pensados por elas para a resolução de problemas e fomenta os processos de raciocínio.

Para Tortola (2012, p. 7) a Modelagem Matemática potencializa o ensino e a aprendizagem da Matemática favorecendo 0 uso da linguagem matemática e demais linguagens utilizadas pelos alunos no cotidiano, contribui para que os "estudantes se tornem cidadãos críticos, capazes de participar ativamente nas tomadas de decisões em prol da sociedade".

Segundo English (2009, p. 162) as crianças devem aprender a lidar com situações complexas e que façam sentido para elas de modo que sejam capazes de matematizá-las significativamente e "que envolvam mais do que apenas contagens e medidas simples". Para a autora situações complexas são situações da vida real e que se baseiam no conhecimento e experiências existentes das crianças, sem distinção de disciplinas. Nesse estudo, a autora aborda o caráter interdisciplinar da modelagem matemática, uma vez que promove discussões que vão para além da matemática, incorporando outras disciplinas e sendo uma boa sugestão para orientar o trabalho de projetos interdisciplinares.

Dessa forma, a "Modelagem pode ser inserida já nos primeiros anos escolares, pois esse nível de ensino é a base para as próximas aprendizagens [...]" (SILVA; KLÜBER, 2012, p. 239) e sua inserção nesse contexto é um meio de ver a necessidade de utilizar a matemática em seus problemas cotidianos e desmitificar que a matemática é um conhecimento necessário somente para 0 futuro escolar, sem relação alguma com a sociedade (SILVA; KLÜBER, 2012).

Diante dessa defesa pela modelagem matemática nos primeiros anos escolares buscamos em eventos científicos como o Encontro Nacional de Educação Matemática, a Conferência Nacional sobre Modelagem na Educação Matemática, o Encontro Paranaense de Educação Matemática e 0 Encontro Paranaense de Modelagem na Educação Matemática publicações que abordam a modelagem matemática no contexto da Educação Infantil. Encontramos apenas dez publicações nos últimos cinco anos ${ }^{3}$.

\footnotetext{
3 Para além desses trabalhos, encontrados nesse período, vale a pena citar o trabalho de Carvalho, Oliveira e Luna (2012), publicado no $3^{0}$ Simpósio Internacional de Pesquisa em Educação Matemática, que embora não esteja dentre os eventos citados, está disponível na internet e foi um dos primeiros trabalhos sobre modelagem matemática desenvolvido na Educação Infantil.
} 
Dentre as publicações, observamos algumas especificidades em relação à prática da modelagem matemática na Educação Infantil, as quais requerem dos professores e dos alunos (re)posicionamentos nos atos de ensinar e de aprender, como a importância do contato visual e da visualização; 0 uso de materiais e de objetos manipuláveis (CARVALHO; OLIVEIRA; LUNA, 2012); 0 uso de brincadeiras e a contação de estórias (SILVA, 2013; ZAMPIROLLI; KATO, 2019); a abordagem de atividades e/ou situações associadas à rotina dos alunos (MARCONDES; SILVA, 2019); a interação dos alunos por meio de rodas de conversa (REZENDE; COUTINHO; TORTOLA, 2019); e "0 uso da oralidade, a expressão por meio de gestos, a recorrência a recursos visuais como desenhos, pinturas, colagens, etc." (REZENDE; FADIN; TORTOLA, 2019, p. 14).

Essas pesquisas mostram a modelagem matemática como uma boa alternativa para se implementar nas práticas pedagógicas da Educação Infantil, pois coloca os alunos frente a situações de seu cotidiano em que noções que eles possuem podem ser discutidas, exploradas e formalizadas e novos conhecimentos e formas de pensar podem ser apreendidos.

Dessa forma, propusemo-nos a pesquisar a mobilização do raciocínio proporcional em uma atividade de modelagem matemática desenvolvida por alunos da Educação Infantil, contexto em que as primeiras relações multiplicativas surgem e passam a ser colocadas em comparação com as relações aditivas estabelecidas até então, assim como surgem (ou passam a ser percebidas) situações em que há a necessidade de se pensar os números em termos relativos e não apenas em termos absolutos, evocando as primeiras ideias e noções associadas à proporcionalidade.

\section{RACIOCÍNIO PROPORCIONAL}

0 raciocínio proporcional é abordado em vários documentos curriculares como a Base Nacional Comum Curricular (BRASIL, 2018), Parâmetros Curriculares Nacionais de Matemática (BRASIL, 1997, 1998) e Diretrizes Curriculares da Educação Básica para a disciplina de Matemática do Estado do Paraná (PARANÁ, 2008). Esses documentos indicam a necessidade e a importância de desenvolver o raciocínio proporcional, dentro e fora do ambiente escolar.

0 raciocínio proporcional está presente em diversas áreas do conhecimento, tais como ciência, música, geografia, e em várias situações e atividades cotidianas,

auxilia no cálculo das melhores compras, investimentos e análise de impostos, auxilia também ao trabalhar com desenhos e mapas, conversão de medidas ou monetárias, aumento ou redução de alguma receita ou para criar várias concentrações de misturas e soluções (ONTARIO, 2012, p. 4).

Está relacionado, portanto, à medição, a relações multiplicativas, a comparações entre quantidades ou valores, à consideração de um número em termos relativos ao invés de termos absolutos (ONTARI0, 2012). É "utilizado para descrever conceitos e pensamentos requeridos para a compreensão de taxas, razões e proporções" (NORTON, 2005, p. 17) que auxiliam no entendimento da trigonometria, da álgebra e outras vertentes da matemática.

Assim, é interessante que desde os primeiros anos escolares os professores explorem algumas noções intuitivas que levem ao desenvolvimento desse raciocínio. Ou seja, que criem e oportunizem situações e experiências nas quais os alunos possam manifestar ideias e formas de pensar que re- 
metam ao raciocínio proporcional, fazendo com que compreendam o contexto do problema e evitem 0 uso de regras e algoritmos sem entender o que estão fazendo.

Para Lamon (2012) mobilizar o raciocínio proporcional implica em compreender os números racionais e os conceitos multiplicativos relacionados a eles. Na Educação Infantil, essa compreensão pode ser desenvolvida por meio de situações que desenvolvem noções informais de taxa, razão e proporção, transformação de quantidades, trabalhar com medidas, quantificar informações qualitativas (ENGLISH, 2006).

Diante das várias possibilidades de ideias e formas de pensar que podem remeter ao raciocínio proporcional, Lamon (2012) as sistematizou em sete aspectos que podem ser interpretados como elementos necessários para a mobilização do Raciocínio Proporcional. São eles: 5 fontes de significado para a/b, Medição, Raciocínio Progressivo e Regressivo, Partilha e Comparação, Unitização, Raciocínio Relativo, Quantidades e Covariação.

A Figura 1 apresenta esses aspectos organizados por Lamon (2012) em uma rede, constituída por sete balões, que indicam aspectos do conhecimento matemático que sinalizam a mobilização do raciocínio proporcional, e por segmentos que ligam esses balões, mostrando que, embora cada balão apresente pontualmente um conceito, eles estão interligados em uma rede, representando diversas ideias e conceitos do conhecimento matemático que são constituídos pelos alunos por meio de diferentes vivências ao longo de sua trajetória escolar (CYRINO et al., 2014). Esses segmentos que se entrecruzam formando "nós", podem ser interpretados como diferentes caminhos, formas de pensar matematicamente, que levam a compreensão de conceitos e ideias associadas ao Raciocínio Proporcional.

Figura 1 - Rede Lamon.

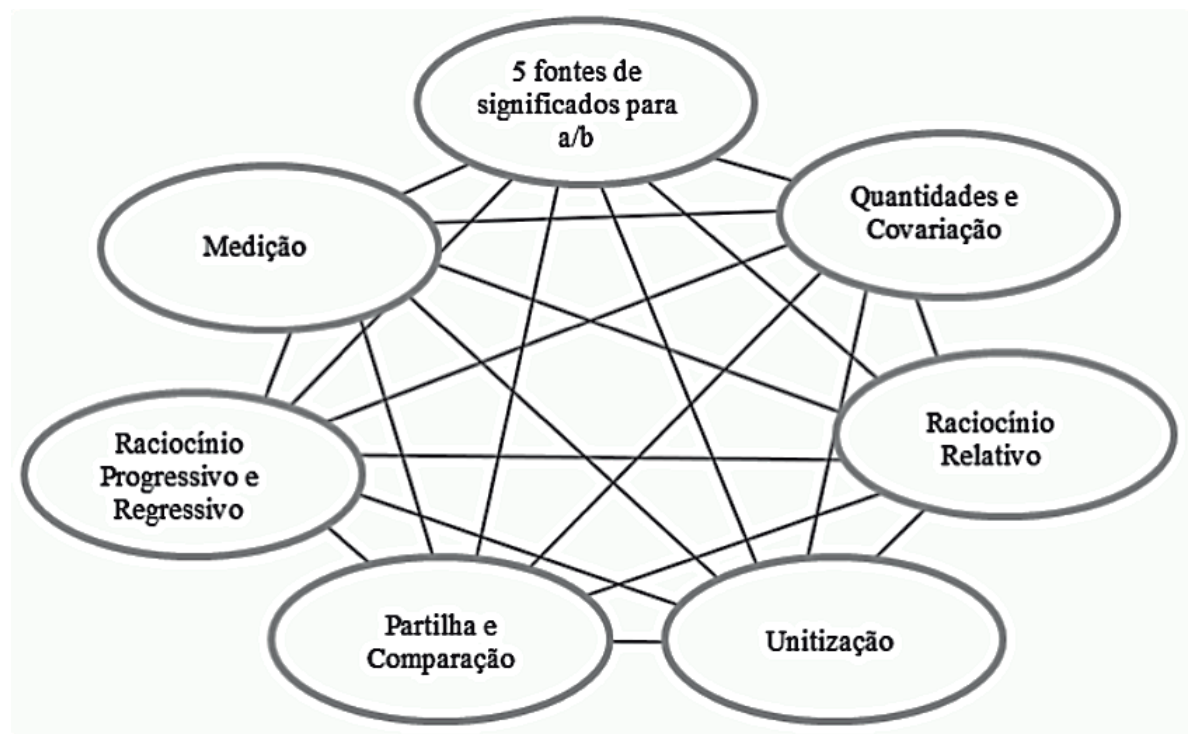

Fonte: Lamon (2012, p. 10).

As 5 fontes de significados para $a / b$ indicam a necessidade de se compreender as diferentes formas de interpretar o registro de um número racional, escrito na forma a/b, em diferentes contextos, 
ou seja, as frações e seus subconstrutos. Segundo Lamon (2012), esse registro pode indicar cinco fontes de significados (subconstrutos): relação parte-todo (medida), razão, taxa, quociente e operador.

"A ideia de medida, ou de medição, está presente na constituição do conhecimento da representação fracionária dos números racionais e consequentemente está na base do desenvolvimento/ mobilização do Raciocínio Proporcional" (CYRINO et al., 2014, p. 52). Medir significa comparar grandezas de mesma natureza, "baseia-se na visualização e quantificação direta de objetos (quantidades discretas ou contínuas)" (OLIVEIRA, 2016, p. 4). Ao trabalhar com medições na Educação Infantil é preciso partir de medidas não padronizadas (palmo, pé, mão, passo, dedo), para que posteriormente as crianças possam perceber a necessidade das medidas padronizadas (LOPES; GRANDO, 2012).

0 Raciocínio Progressivo e Regressivo pode ser entendido como um:

procedimento mental que envolve calcular de maneira progressiva, a partir de uma fração qualquer, as relações de proporcionalidade equivalentes ao inteiro (à unidade referencial) e em seguida encontrar relações proporcionais para outras frações quaisquer desse inteiro, a partir dessas relações já encontradas, ou vice-versa (OLIVEIRA, 2014, p. 62).

A partilha e comparação é outro aspecto associado ao raciocínio proporcional por Lamon (2012). A partilha, ou divisão equitativa, refere-se ao ato de dividir uma quantidade, seja ela discreta ou contínua, em seções disjuntas, finitas e iguais, ou seja, dividir de modo que as partes resultantes não se sobreponham e todas façam parte da unidade (LAMON, 2012; CYRINO et al., 2014). Esse procedimento associado à comparação permite que sejam estabelecidas relações entre as partes e entre as partes e 0 todo, procedimentos frequentemente utilizados na escrita do registro fracionário. Essa ideia de efetuar divisões em uma unidade, podendo em seguida estabelecer comparações entre as partes resultantes está também relacionada à medição.

A unitização pode ser compreendida como um processo de reorganizar uma unidade em subconjuntos de diferentes tamanhos (OLIVEIRA, 2014). Ou seja, é a reorganização ou (re)agrupamento de uma grandeza em subgrupos que preservam a mesma quantidade total, cujos inteiros ou unidades referenciais permanecem iguais, porém representados por formas fracionárias diferentes (CYRINO et al., 2014). Com esse entendimento a unitização está intimamente ligada ao conceito de frações equivalentes.

Por meio do raciocínio relativo, de acordo com Cyrino et al. (2014, p. 54)

os indivíduos são capazes de mensurar quantidades mais complexas, abstratas, que não podem ser medidas diretamente com a utilização de instrumentos específicos ou contagem imediata, são quantidades resultantes de comparações/relações entre grandezas de naturezas por vezes distintas como velocidade, densidade, inclinações, concentração, etc.

0 aspecto quantidades e covariação indica a capacidade que os alunos têm em "identificar e mensurar quantidades, além de perceber de que maneira essas quantidades variam (covariam) quando relacionadas" (CYRINO et al., 2014, p. 54).

São nesses aspectos, pontuados por Lamon (2012), que nos pautamos para investigar as manifestações do raciocínio proporcional nas ideias e formas de pensar apresentadas pelos alunos da Educação Infantil em seus encaminhamentos para a atividade de modelagem matemática. 


\section{ASPECTOS METODOLÓGICOS E CONTEXTO DA PESQUISA}

Com a intenção de investigar como alunos da Educação Infantil mobilizam o raciocínio proporcional em uma atividade de modelagem matemática, analisamos uma atividade de modelagem matemática desenvolvida em junho de 2019, com 17 alunos de uma turma de maternal III, de 3 e 4 anos, em um Centro Municipal de Educação Infantil, público, localizado no Centro Ocidental Paranaense, durante suas aulas regulares.

Os dados foram coletados por meio de gravações em áudio, vídeo, registros fotográficos, anotações em diário de campo dos pesquisadores e produções escritas dos alunos.

As análises foram orientadas a partir de nosso entendimento de pesquisa qualitativa, cujo foco está na compreensão dos resultados e nas implicações que eles têm para o campo da Educação Matemática, particularmente para a Modelagem Matemática no contexto da Educação Infantil (LUDKE; ANDRÉ, 2014).

Dessa forma, fizemos inicialmente uma descrição da atividade, logo após o seu desenvolvimento, contemplando as informações presentes em nossos registros e nossas impressões. Para este artigo ${ }^{4}$ refinamos essa descrição e destacamos os principais encaminhamentos e discussões dos alunos para a atividade. Junto à descrição, sinalizamos trechos em que identificamos ideias e formas de pensar que, baseados em Lamon (2012), inferimos ser aspectos que indicam a mobilização do raciocínio proporcional. Por fim, elaboramos um quadro que sistematiza e apresenta como os alunos da Educação Infantil mobilizaram o raciocínio proporcional na atividade de modelagem matemática.

A atividade, que integra a pesquisa de mestrado da primeira autora (COUTINHO, 2020), orientada pelo segundo autor, foi desenvolvida junto a outras atividades de modelagem matemática, as quais foram organizadas em três momentos, conforme sugestão de Almeida, Silva e Vertuan (2012), de modo que a cada atividade os alunos tiveram a oportunidade de familiarizar-se com ações e procedimentos específicos da modelagem matemática, adquirindo mais autonomia a cada momento. A atividade escolhida para análise se enquadra no segundo momento, uma vez que o tema foi proposto pela professora, mas coube aos alunos definir os "procedimentos extramatemáticos e matemáticos adequados para a realização da investigação" (ALMEIDA; SILVA; VERTUAN, 2012, p. 26).

Com a intenção de manter a identidade dos alunos preservada, nos referimos a eles neste artigo da seguinte forma: A1 o primeiro aluno de uma lista que organizamos, A2 o segundo aluno, e assim por diante, até 0 código A17. À professora pesquisadora atribuímos 0 código P, às professoras regentes da turma $\mathrm{R} 1 \mathrm{e} \mathrm{R} 2 \mathrm{e}$ à estagiária $\mathrm{E}$.

\section{ANÁLISE DA ATIVIDADE: BALANÇAR OU EQUILIBRAR NA GANGORRA?}

No desenvolvimento da atividade "Balançar ou equilibrar na gangorra?", os alunos investigaram os fatores que determinam seu movimento e seu equilíbrio. A partir de uma conversa no parque os alunos brincaram e investigaram diversas situações com a orientação da professora pesquisadora, que levou à produção de modelos matemáticos do movimento (ou das posições) da gangorra, registrados por meio de desenhos.

Nossa intenção com o desenvolvimento dessa atividade foi que os alunos percebessem relações entre grandezas, orientando-os com questões como: 0 que acontece com os lados da gangorra

4 Um ensaio dessa investigação foi publicado no XV Encontro Paranaense de Educação Matemática (EPREM) em Coutinho e Tortola (2019). Este artigo é resultado de reflexões após o evento e a defesa da dissertação da primeira autora, com um refinamento nas análises e discussões. 
quando um deles sobe? 0 que acontece quando os pesos das pessoas são muito diferentes? Ou são iguais? Vejamos os encaminhamentos dos alunos.

Para problematizar a situação, fase de inteiração, conforme Almeida, Silva e Vertuan (2012), a professora pesquisadora pediu para que uma aluna subisse em um dos lados da gangorra e perguntou se ela conseguiria balançar sozinha. Em resposta a esse questionamento, A8 falou que precisava de mais crianças para que a brincadeira funcionasse. Essa maneira de pensar sobre a quantidade de crianças nos leva a inferir a mobilização do aspecto do raciocínio proporcional quantidades e covariação (LAMON, 2012), pois a aluna demonstrou compreensão de que com apenas uma criança seu lado da gangorra não sairia do chão, ou seja, não haveria variação nas alturas de ambos os lados da gangorra, por isso duas crianças eram necessárias, uma para cada lado da gangorra.

Para fomentar as discussões, a professora pesquisadora subiu em um dos lados da gangorra e pediu que do outro lado sentasse uma aluna. Imediatamente o lado em que estava a professora pesquisadora desceu todo, deixando a aluna no alto. Embora nessa situação esteja na gangorra, além da criança, a professora pesquisadora, a diferença de pesos entre professora e aluna fez com que não ocorresse nenhum movimento, mostrando que quando um lado é muito mais pesado que o outro, ele se mantém posicionado no chão. A10, ao observar a situação, tentou abaixar o lado da gangorra em que estava a colega, como mostra a Figura 2.

Figura 2 - Tentativa de abaixar o lado mais alto da gangorra.

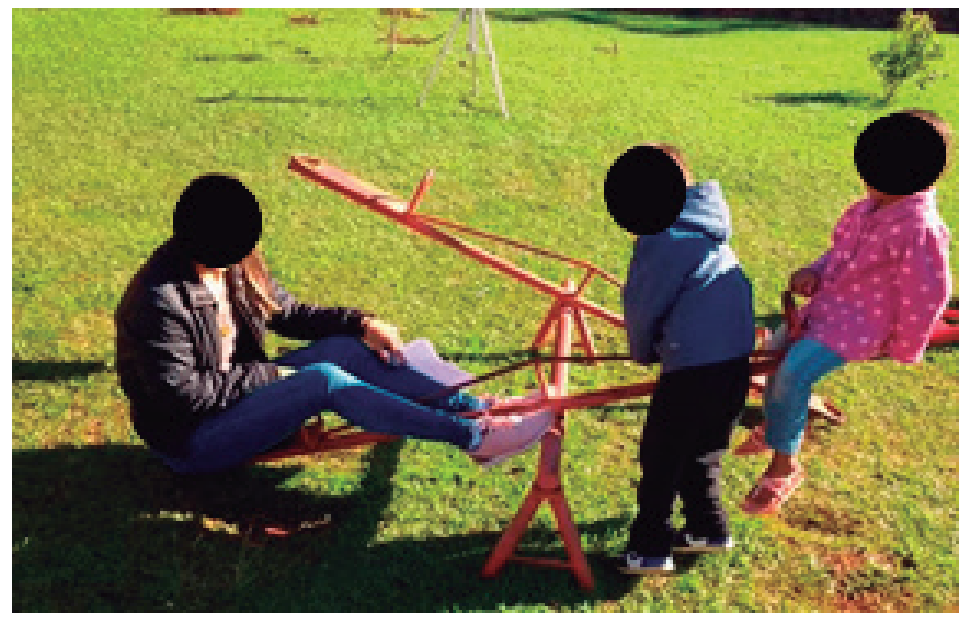

Fonte: Dos autores.

Ao perceber que a colega estava "presa" nas alturas o aluno tentou somar seu peso ao dela, para que 0 seu lado pudesse abaixar e, consequentemente, a gangorra balançar e a brincadeira acontecesse, pois como mostra a Figura 2 o movimento da gangorra ficou impossibilitado. Isso sugere que 0 aluno tem ideia de como covariam as grandezas "peso" e "posição" da gangorra, ou seja, para abaixar o lado mais alto é preciso mais peso, o que denota a capacidade do aluno de identificar e mensurar quantidades, além de perceber como essas quantidades estão associadas, conforme Lamon (2012) explica 0 aspecto quantidades e covariação.

A5 ao ver A10 tentando ajudar a colega, concluiu que para que a gangorra se movimentasse "tem que ser [...] criança só na gangorra", ou seja, A5 levantou a hipótese de que o balanço aconteceria 
somente se apenas crianças brincassem, atrelando o funcionamento da gangorra com a proximidade dos pesos das pessoas em cada lado, o que é reafirmado quando fala para a professora pesquisadora a comparação que fez entre o peso dela e da aluna "porque você é muito grande [é maior] do que ela". Essa constatação sinaliza a fase de matematização pontuada por Almeida, Silva e Vertuan (2012). Portanto, para acontecer o movimento de balanço os pesos das pessoas nos dois lados da gangorra deveriam ser próximos, sendo inviável, por exemplo, a brincadeira entre um adulto e uma criança, pois a diferença de pesos entre eles é muito grande, conforme constatou o aluno A5. Essa constatação pode ser interpretada como indício de dois aspectos do raciocínio proporcional: raciocínio relativo e partilha e comparação (LAMON, 2012).

0 primeiro foi sinalizado quando A5 observou que o peso da professora é maior que o da colega e mesmo com a ajuda de A10, seu lado da gangorra não desceu. Isso o levou a concluir que com a professora e uma criança (ou duas, de acordo com suas observações) não é possível a gangorra balançar. Ou seja, ele conseguiu estabelecer sem realizar medições com instrumentos de medida uma comparação entre a relação do peso da professora com seu lado da balança e a relação do peso da aluna com seu lado da balança e, de acordo com Cyrino et al. (2014, p. 54), o raciocínio relativo remete a mensurar "quantidades resultantes de comparações/relações entre grandezas de naturezas por vezes distintas".

Esse raciocínio, que fez com que 0 aluno concluísse que com a professora a gangorra não balançaria, o levou a pensar em uma solução ou consequência, que foi que apenas crianças podem brincar, pois só com duas crianças a gangorra balançaria, uma vez que as crianças apresentam pesos próximos, o que sugere a ideia de partilha e comparação, uma vez que se configura como uma distribuição equitativa (ou pelo menos se aproxima disso). Esse procedimento associado à comparação permite que sejam estabelecidas relações entre as partes e entre as partes e o todo (LAMON, 2012).

Aproveitando essa situação, a professora pesquisadora abordou a altura máxima da gangorra, ou seja, chamou a atenção dos alunos que existe um limite de altura que cada lado da gangorra pode atingir, como ilustra a Figura 3.

Figura 3 - Altura máxima de um dos lados da gangorra.

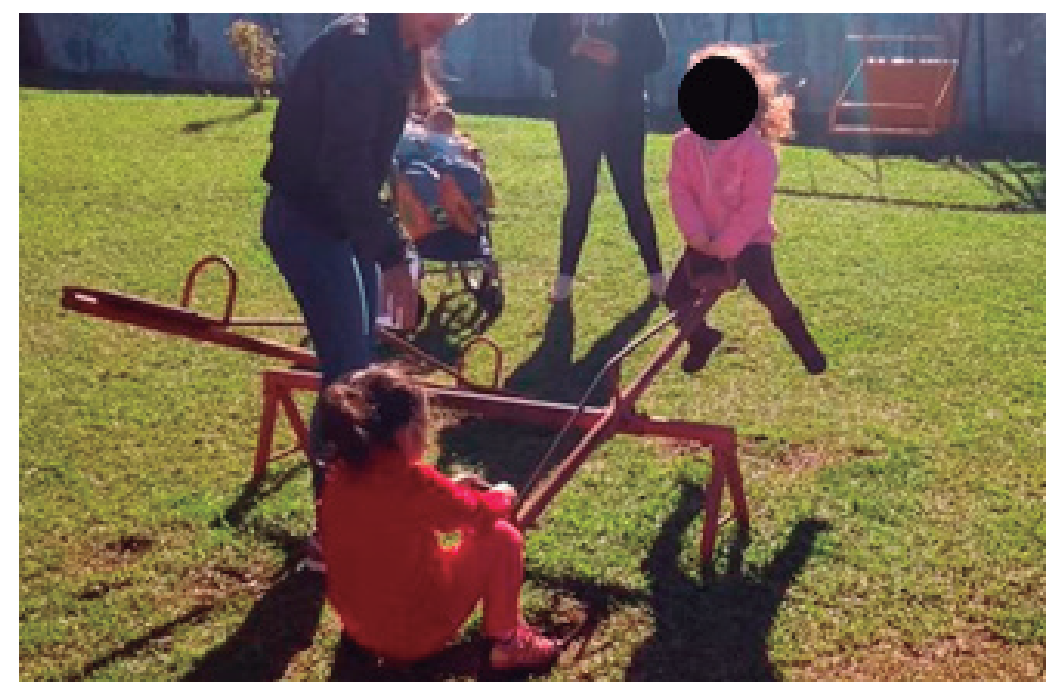

Fonte: Dos autores. 
Quando a professora regente questionou se A2 (à esquerda na Figura 3) conseguiria descer mais que aquela posição, A17 respondeu que não, em seguida a professora regente rebateu: "se A2 não pode ir mais para baixo, A8 pode ir mais para cima?". A17 respondeu novamente que não e, então, a professora pesquisadora explicou que isso acontece porque tem uma altura máxima que a gangorra atinge e disse que essa altura era o seu "limite". Esses questionamentos realizados pela professora regente, fez com que professora pesquisadora chamasse a atenção dos alunos para o fato de que existe uma altura máxima, assim como existe também uma altura mínima. Se analisarmos atentamente esses limitantes, indo um pouco além das discussões feitas com os alunos, observamos que a soma das alturas de ambos os lados da gangorra em relação ao chão, independente da posição, é constante, o que sinaliza 0 aspecto unitização. Segundo Lamon (2012) a unitização refere-se a um processo de reorganizar grandezas, as agrupando ou reagrupando de outras maneiras conservando a quantidade total. Embora as crianças não conseguiram formular essa conjectura tal como sinalizamos, elas conseguiram entender que quando um lado da gangorra atinge sua altura máxima, o outro atinge sua altura mínima, o que pode ser interpretado como um dos primeiros indícios de mobilização desse aspecto.

Existe, sobretudo, uma posição da gangorra em particular, que pode também ser um indício do aspecto unitização, que a professora pesquisadora considerou importante abordar, a posição em que a gangorra se encontra em equilíbrio. Nesse caso, as alturas em ambos os lados tendem a ser iguais. A professora pesquisadora iniciou a discussão dessa posição ainda com A2 e A8 na gangorra, questionando quem estava mais alta. Quando A5 respondeu "A2 e A8", a professora pesquisadora explicou "Isso! As duas estão na mesma posição. Assim, a gente fala que [a gangorra] está em equilíbrio", como mostra a Figura 4.

Figura 4 - Gangorra em equilíbrio.

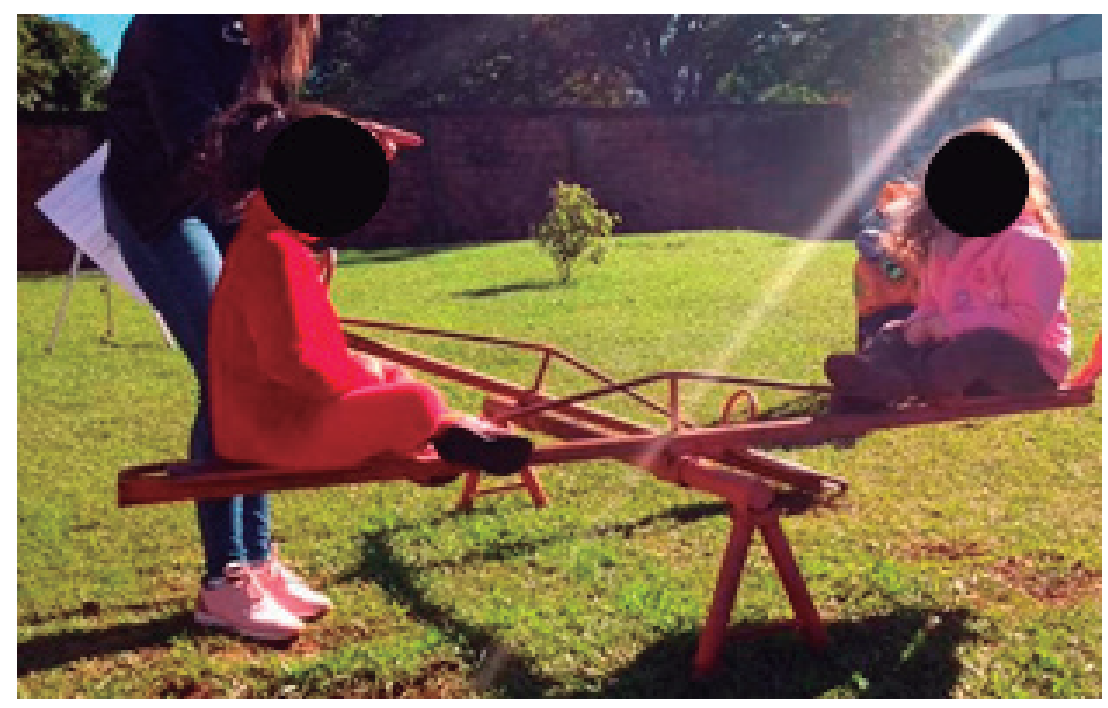

Fonte: Dos autores.

Para explicar sobre o equilíbrio de outro modo, a professora pesquisadora propôs usar pacotes de arroz (de $5 \mathrm{~kg}$ ) e de feijão (de $1 \mathrm{~kg}$ ), conforme mostra a Figura 5. 
Figura 5 - Tentativa de deixar a gangorra em equilíbrio.

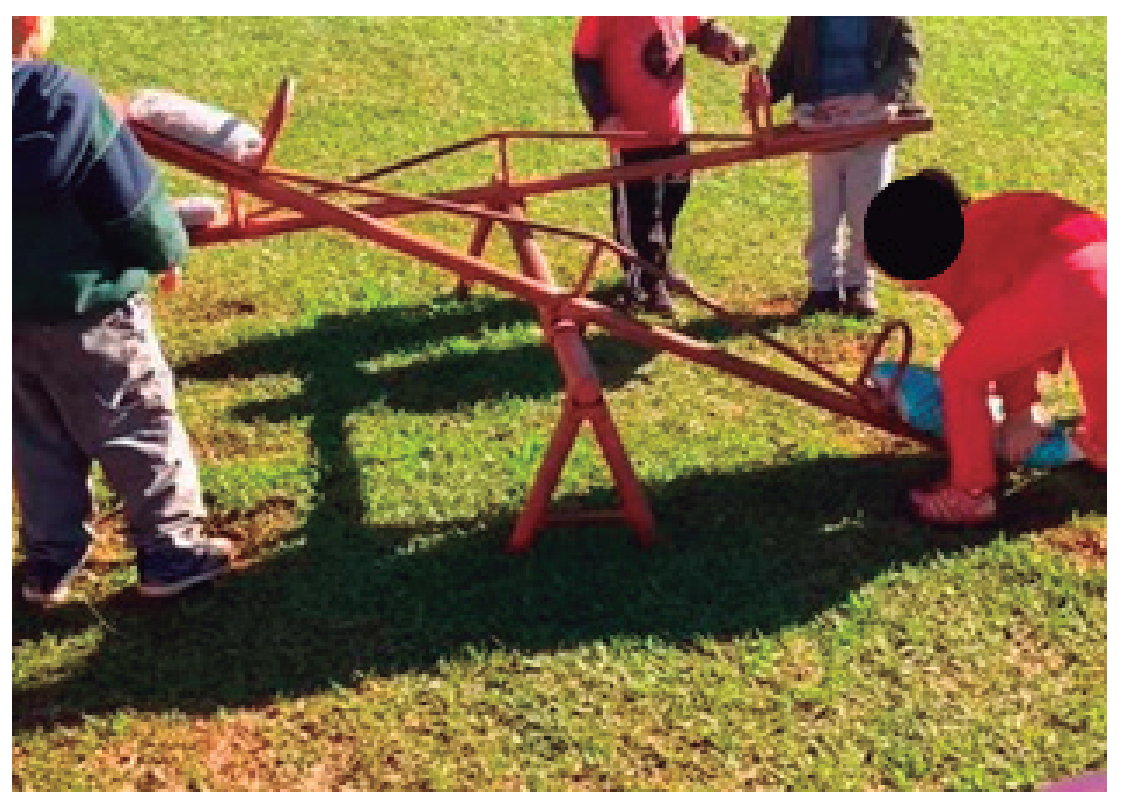

Fonte: Dos autores.

Algumas tentativas de deixar a gangorra em equilíbrio foram feitas. Inicialmente os alunos colocaram um pacote de arroz de um lado e um de feijão do outro e perceberam que a gangorra não ficou em equilíbrio. Sugestões como "colocar mais pacotes de arroz e de feijão" (A8), "colocar mais um feijão" (A17) e "tirar o arroz grande" (A5), sinalizam a compreensão da necessidade de deixar um dos lados mais pesado, no caso o lado que estava o pacote de feijão, ou, de deixar um dos lados mais leve, no caso o lado que estava o pacote de arroz. Essa compreensão se mostra como um indício do aspecto quantidades e covariação, que se confirma quando A2 afirma que para a gangorra ficar em equilíbrio "esse tem que erguer (lado mais pesado) e esse abaixar (lado mais leve)", pois mostra que os alunos compreenderam como as grandezas "peso" e "altura" da gangorra se relacionam e como elas variam.

A partir do momento em que a professora pesquisadora revelou os pesos dos pacotes de alimentos, os alunos puderam usar esses pesos como parâmetro de comparação, e compreenderam o porquê a posição da gangorra permaneceu inalterada quando acrescentaram apenas um pacote de feijão (1 kg) do lado mais leve da gangorra, que já tinha um pacote de feijão. Como do outro lado havia um pacote de arroz (5 kg), usaram a relação aditiva (colocar mais um) e foram colocando os pacotes de feijão um a um até encontrar o equilíbrio, cinco quilogramas (como sugeriu A17). Esse tipo de raciocínio é o ponto de partida para que os alunos compreendam posteriormente relações multiplicativas, que é uma das ideias mais importantes do raciocínio proporcional (VAN DE WALLE, 2009). Essa possibilidade de comparar os pesos, contando diretamente, caracteriza 0 aspecto medição que Lamon (2012) pontuou. A Figura 6 mostra a gangorra em equilíbrio, com cinco pacotes de feijão de um lado (à esquerda) e um pacote de arroz do outro (à direita). 
Figura 6 - Gangorra equilibrada com os alimentos.

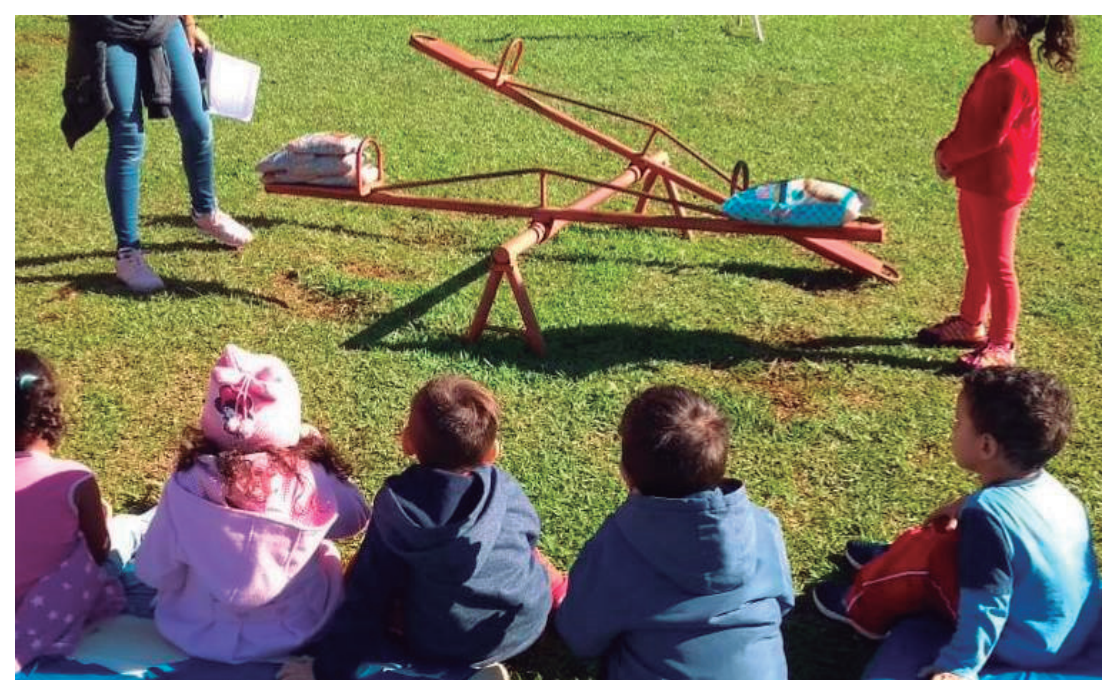

Fonte: Dos autores.

Ao retornar para a sala de aula, os alunos iniciaram a fase resolução, conforme Almeida, Silva e Vertuan (2012), e registraram suas conclusões por meio de desenhos, os quais se constituíram como modelos matemáticos do movimento (ou da posição) da gangorra. Nesses modelos observamos alguns indícios de mobilização dos aspectos já citados. A11, por exemplo, ao ser questionada sobre seu desenho (Figura 7), falou que sua gangorra estava parada (representada pela linha horizontal), ou seja, a aluna compreendeu a ideia de equilíbrio e a relação existente entre as grandezas "peso" e "altura" da gangorra, sinalizando os aspectos unitização e quantidades e covariação.

Figura 7 - Modelo matemático de A11.

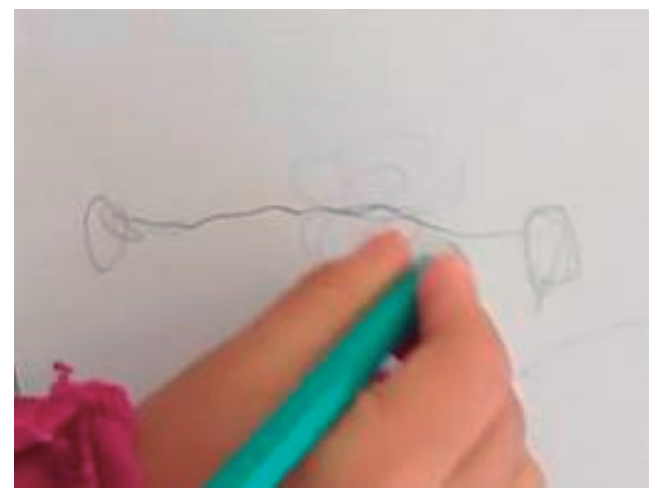

Fonte: Dos autores.

A5, ao explicar seu desenho (figura 8), sinalizou sua compreensão sobre o comportamento de grandezas diretamente proporcionais, referentes ao aspecto quantidades e covariação, conforme mostra 0 diálogo a seguir: 
A5: Eu vou fazer mais porque precisa de mais pessoas.

$\boldsymbol{P}$ : Precisa de mais pessoas para fazer o quê?

A5: Porque eu vou fazer mais gangorras.

Esse aluno sugeriu em seu modelo matemático (Figura 8) duas grandezas, "número de pessoas" e "quantidade de gangorras", e como elas se relacionam, indicou que quanto mais gangorras, mais pessoas são necessárias para balançar.

Figura 8 - Relação entre gangorras e pessoas.

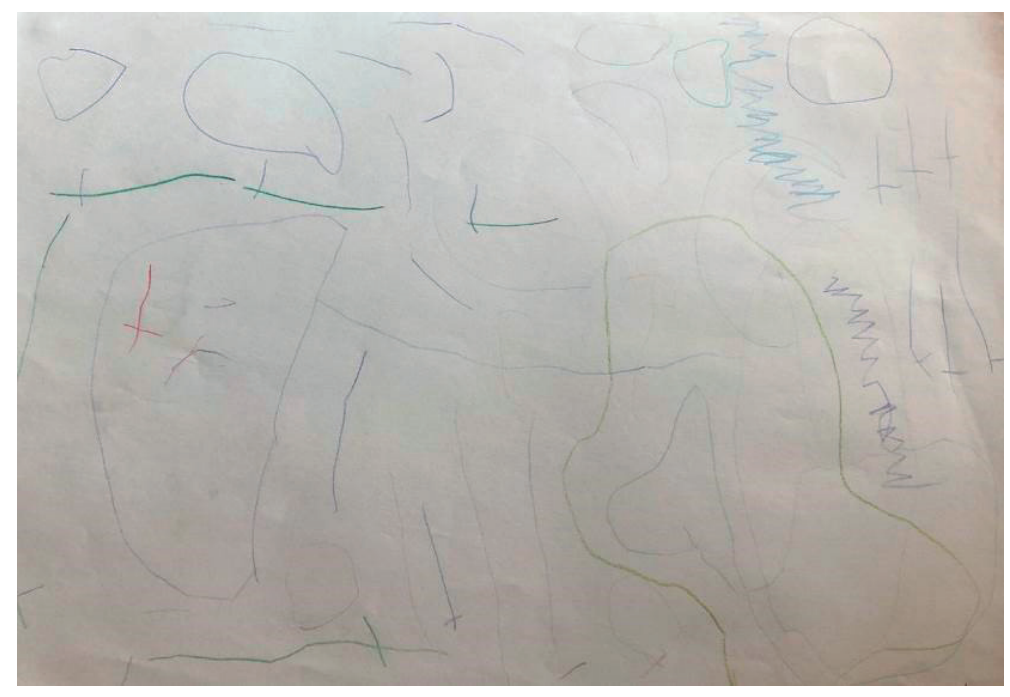

Fonte: Dos autores.

A professora pesquisadora questionou o que os "círculos" representavam e por que uns eram menores e outros maiores e A5 respondeu: "é porque tem que ser uma pessoa magrela e uma pessoa forte", ou seja, o aluno ilustrou a ideia de que sem impulso, com pesos iguais, a balança ficaria em equilíbrio, ou seja, nenhum movimento ocorreria. Por outro lado, podemos observar que a diferença nos tamanhos dos desenhos não é significativa, pois ele compreendeu que pesos discrepantes também não permitem movimento, o lado mais pesado descerá e permanecerá posicionado ao chão. Essas conclusões sinalizam a mobilização do raciocínio relativo (LAMON, 2012).

Essa conversa entre professora pesquisadora e alunos configura-se como a fase Interpretação de Resultados e Validação, explicitada por Almeida, Silva e Vertuan (2012), uma vez que deu aos alunos a oportunidade de explicar seus modelos e refletir sobre sua validade. Após a confecção dos desenhos, modelos matemáticos, os alunos socializaram suas produções com os colegas, momento em que observamos as relações e comparações estabelecidas entre os modelos criados e as gangorras do parque, contribuindo para a validação dos modelos produzidos.

A atividade de modelagem matemática relacionada à gangorra mostrou-se como uma alternativa para explorar o raciocínio proporcional, pois além de promover a problematização e a investigação de uma situação que tem como tema um brinquedo com o qual brincam com frequência, fez com que os alunos construíssem e se apropriassem de conhecimentos por meio de suas ações, estratégias e interações com colegas e professoras, o que possibilitou aprendizagens, desenvolvimento e 
socialização. Diante das explorações realizadas, os alunos deixaram claro que o legal da brincadeira é balançar e durante a atividade mostraram interesse, entusiasmo e curiosidade pelo tema.

Com a atividade da gangorra identificamos a abordagem de alguns aspectos do raciocínio proporcional, apontados por Lamon (2012), como quantidades e covariação, raciocínio relativo, partilha e comparação, unitização e medição, uma vez que os alunos compararam, mediram e relacionaram quantidades relativas a diferentes grandezas (como "peso" e "altura" da gangorra) e reconheceram diferentes maneiras de expressar uma mesma quantidade.

No Quadro 1 apresentamos uma síntese dos aspectos do raciocínio proporcional mobilizados e em quais situações isso aconteceu no desenvolvimento da atividade.

Quadro 1 - Aspectos do raciocínio proporcional mobilizados na atividade da gangorra.

\begin{tabular}{|c|c|}
\hline $\begin{array}{c}\text { Aspecto do raciocínio } \\
\text { proporcional (LAMON, 2012) }\end{array}$ & Situações em que 0 aspecto foi mobilizado \\
\hline $\begin{array}{l}\text { Quantidades e } \\
\text { covariação }\end{array}$ & $\begin{array}{l}\text { A8 percebeu que precisa ter mais que uma criança na gangorra para balançar (com apenas uma criança seu } \\
\text { lado não saiu do chão, ou seja, não houve variação nas alturas de ambos os lados da gangorra); } \\
\text { Professora pesquisadora subiu em um dos lados da gangorra, com A17 do outro lado a gangorra não se } \\
\text { moveu, "você é muito grande [maior] do que ela" (A5) (compreensão de que quando há discrepância entre } \\
\text { os pesos dos dois lados a gangorra não balança); } \\
\text { Tentativa de A10 de abaixar o lado da gangorra no qual estava sua colega A17, que é muito mais leve que a } \\
\text { professora pesquisadora (entendimento de que quanto mais pesado um lado da gangorra mais baixa será } \\
\text { sua altura, até atingir a altura mínima, no caso o chão, ou, de que quanto mais leve um lado, maior será sua } \\
\text { altura, até atingir a altura máxima); } \\
\text { Tentativa dos alunos em deixar a gangorra em equilíbrio "colocar mais um feijão" (A17), "tirar o arroz grande" } \\
\text { (A5) (identificação de qual lado da gangorra tem que subir ou descer para que a gangorra fique em equilíbrio); } \\
\text { Explicação de A11 para seu modelo matemático que descreve uma gangorra em equilíbrio (percepção da } \\
\text { relação existente entre as grandezas peso e altura); } \\
\text { Percepção de A5 que precisa desenhar mais pessoas para a quantidade de gangorras que desenhou (gran- } \\
\text { dezas diretamente proporcionais). }\end{array}$ \\
\hline Raciocínio Relativo & $\begin{array}{l}\text { Percepção dos alunos sobre a inviabilidade da brincadeira entre um adulto e uma criança (constatação da } \\
\text { diferença de pesos entre a professora pesquisadora e A17 a partir da observação de que a gangorra perma- } \\
\text { neceu imóvel); } \\
\text { Para evitar que a gangorra fique em estado de equilíbrio A5 desenhou círculos de diferentes tamanhos, para } \\
\text { indicar uma "pessoa magrela" e uma "pessoa forte" (o aluno percebeu que para ficar em equilíbrio os pesos } \\
\text { de ambos os lados das gangorras têm que ser iguais). }\end{array}$ \\
\hline Partilha e comparação & $\begin{array}{l}\text { Compreensão de A17 sobre a funcionalidade da gangorra, "tem que ser só crianças na gangorra" (percepção } \\
\text { da necessidade de existir uma proximidade entre os pesos de ambos os lados da gangorra, como os pesos } \\
\text { de duas crianças). }\end{array}$ \\
\hline Unitização & $\begin{array}{l}\text { Exploração da questão "se A2 não pode ir mais para baixo, A8 pode ir mais para cima?" (compreensão de } \\
\text { que existe uma altura máxima e uma altura mínima que os lados da gangorra podem atingir, e que variação } \\
\text { de um lado se dá em conformidade com o outro, ou seja, a soma das alturas de ambos os lados da gangorra } \\
\text { em relação ao chão, independente da posição, é constante); } \\
\text { A5 respondeu que A2 e A8 estão mais altas no momento em que a gangorra ficou em equilíbrio (Indistinção } \\
\text { de qual aluna está mais alta quando a gangorra está em equilíbrio, pois as alturas de ambos os lados são } \\
\text { iguais); } \\
\text { Percepção dos alunos sobre as alturas dos lados da gangorra quando foi colocado um pacote de arroz de } \\
\text { cinco quilogramas e cinco pacotes de feijão de um quilograma (exploração de que as alturas em ambos os } \\
\text { lados ficaram iguais); } \\
\text { Modelo matemático de A11 (desenhou uma linha horizontal para indicar que a gangorra está em equilíbrio). }\end{array}$ \\
\hline Medição & $\begin{array}{l}\text { Os alunos usaram a relação aditiva }(+1) \text { para colocar os pacotes de feijão de um lado da gangorra até ela } \\
\text { ficar em equilíbrio quando há no outro lado um pacote de arroz (comparação de pesos, contagem direta). }\end{array}$ \\
\hline
\end{tabular}

Fonte: Dos autores. 
Essa síntese mostra que durante a atividade foram discutidos o movimento e algumas posições específicas das gangorras, como quando ela fica em equilíbrio. Essas discussões levaram os alunos a mobilizar vários aspectos do raciocínio proporcional, sem a necessidade de usar mecanismos prontos e automatizados.

\section{CONSIDERAÇÕES FINAIS}

Considerando nossa crença na viabilidade de atividades de modelagem matemática em diferentes níveis de escolaridade (ENGLISH, 2006; 2009; FOX, 2006; ALMEIDA; SILVA; VERTUAN, 2012; TORTOLA; ALMEIDA, 2013; BASSANEZI, 2015); na Educação Infantil como um contexto promissor, no qual os alunos usam estratégias e ideias próprias para a solução de problemas, sem 0 uso de mecanismos e procedimentos prontos e automatizados (GRANDO; MOREIRA, 2012) e, por isso, mostra-se como uma etapa oportuna para o desenvolvimento de ideias e conceitos, formas de pensar e raciocinar; e na importância do desenvolvimento do raciocínio proporcional para a matemática, particularmente no que diz respeito ao entendimento de porcentagens, taxas de variação, trigonometria, álgebra e outras vertentes (NORTON, 2005; LAMON, 2012); nosso intuito com esta pesquisa foi investigar como alunos da Educação Infantil mobilizam o raciocínio proporcional em uma atividade de modelagem matemática?

Os dados analisados revelam que cinco dos sete aspectos pontuados por Lamon (2012) foram mobilizados pelos alunos durante a atividade "Balançar ou equilibrar na gangorra?": quantidades e covariação, raciocínio relativo, partilha e comparação, unitização e medição.

Embora não encontramos indícios de mobilização dos aspectos raciocínio progressivo e regressivo e 5 fontes de significados para a/b, identificamos situações que podem ser exploradas pelo professor de modo a provocar a mobilização de tais aspectos. 0 raciocínio progressivo e regressivo pode ser explorando, por exemplo, no momento em que os alunos tentam equilibrar a gangorra com os pacotes de alimentos. Poderíamos questioná-los sobre qual a quantidade de pacotes de feijão necessária se colocarmos de um lado dois pacotes de arroz. Nessa ocasião poderíamos explorar também uma das 5 fontes de significados para a/b, a relação parte-todo, por exemplo, levando-os a perceber que o peso de um pacote de arroz corresponde ao peso de cinco pacotes de feijão, ou ainda, que o peso de um pacote de feijão corresponde a $1 / 5$ do peso de um pacote de arroz.

A atividade de modelagem matemática desenvolvida, portanto, mostrou grande potencial para a mobilização do raciocínio proporcional, uma vez que ao interpretar e compreender a situação-problema, os alunos tiveram que identificar grandezas, observar seus comportamentos e inferir relações entre elas.

Claro que muitas das mobilizações observadas dependem, majoritariamente, do contexto da situação-problema, porém, não se pode negar que foram favorecidas por ações e procedimentos característicos de uma atividade de modelagem matemática.

Nesse sentido, concluímos que a modelagem matemática é uma alternativa viável a ser utilizada nas aulas da Educação Infantil para provocar a mobilização do raciocínio proporcional e de outros temas, conforme observamos, como contagem, comparação, correspondência biunívoca, etc., para além das discussões extramatemáticas que surgiram e podem atribuir à atividade um caráter interdisciplinar.

\section{REFERÊNCIAS}

ALMEIDA, L. W.; SILVA, K. P.; VERTUAN, R. E. Modelagem Matemática na Educação Básica. São Paulo: Contexto, 2012. 
BASSANEZI, R. C. Modelagem matemática: teoria e prática. São Paulo: Contexto, 2015.

BRASIL. Ministério da Educação. Base Nacional Comum Curricular. Brasília, 2018.

BRASIL. Ministério da Educação. Secretaria de Educação Fundamental. Parâmetros curriculares nacionais: matemática (10 e $2^{0}$ ciclos do Ensino Fundamental). Brasília: MEC/SEF, 1997.

BRASIL. Ministério da Educação. Secretaria de Educação Fundamental. Parâmetros curriculares nacionais: matemática ( $3^{\circ}$ e $4^{0}$ ciclos do Ensino Fundamental). Brasília: MEC/SEF, 1998.

CARVALHO, L. S. S.; OLIVEIRA, L. A.; LUNA, A. V. A. Modelagem Matemática na Educação Infantil: um estudo sobre a proteção solar com crianças de três anos. In: SIMPÓSIO INTERNACIONAL DE PESQUISA EM EDUCAÇÃO MATEMÁTICA, 3., Fortaleza. Anais... Recife: SIPEMAT, 2012.

COSTA, S.; PONTE, J. P. 0 raciocínio proporcional dos alunos do $2{ }^{\circ}$ ciclo do ensino básico. Revista da Educação, Lisboa, v.16, n. 2, p. 65-100, 2008.

COUTINHO, L. Modelagem matemática e raciocínio proporcional na Educação Infantil. 2020. 153 p. Dissertação (Mestrado Profissional em Ensino de Matemática) - Universidade Tecnológica Federal do Paraná. Londrina, 2020.

COUTINHO, L.; TORTOLA, E. Modelagem matemática e raciocínio proporcional na Educação Infantil. In: ENCONTRO PARANAENSE DE EDUCAÇÃO MATEMÁTICA, 15., Londrina. Anais... Londrina: UTFPR / UEL, 2019.

CYRINO, M. C. C. T. et al. Formação de professores em comunidades de prática: frações e raciocínio proporcional. Londrina: UEL, 2014.

ENGLISH, L. D. Mathematical modeling in the primary school: children's construction of a consumer guide. Educational Studies in Mathematics, v. 63, n. 3, p. 303-323, 2006.

ENGLISH, L. D. Promoting interdisciplinarity through mathematical modelling. ZDM, v. 41, n. 1-2, p. 161-181, 2009.

FOX, J. A justification for Mathematical Modelling Experiences in the Preparatory Classroom. In: GROOTENBOER, PETER AND ZEVENBERGEN, ROBYN AND CHINNAPPAN, MOHAN (Eds.). Proceedings 29th annual conference of the Mathematics Education Research Group of Australasia, p. 221-228, Canberra, Australia, 2006.

GRANDO, R. C.; MOREIRA, K. G. Como crianças tão pequenas, cuja maioria não sabe ler nem escrever, podem resolver problemas de matemática? In: CARVALHO, M. A. B. (Org.). Matemática e Educação Infantil: investigações e possibilidades de práticas pedagógicas. Petrópolis, Vozes, 2012. p. 121- 143.

LAMON, S. J. Teaching fractions and ratios for understanding: Essential content knowledge and instructional strategies for teachers. 3th edition. New York: Routledge, 2012.

LOPES, C. E.; GRANDO, R. C. Resolução de problemas na educação matemática para a infância. In: ENCONTRO NACIONAL DE DIDÁTICA E PRÁTICAS DE ENSINO, 16., 2012, Campinas. Anais... Campinas: SBEM, 2012.

LUDKE, M.; ANDRÉ, M. E. D. A. Pesquisa em Educação: abordagens qualitativas. 2. ed. Rio de Janeiro: E. P.U., 2014. 
MACHADO, S. R. C. A inserção da Modelagem Matemática nas séries iniciais. In: ENCONTRO GAÚCHO DE EDUCAÇÃO MATEMÁTICA, 10., 2009, ljuí. Anais... ljuí, Unijuí, 2009.

MARCONDES, C. F.; SILVA, V. da S. Modelagem matemática na educação infantil: considerações a partir de uma prática educativa com crianças de 3 e 4 anos. Revista de Educação Matemática, São Paulo, v. 16, n. 21, p. 71-87, 2019.

NORTON, S. J. The construction of proportional reasoning. In: CHICK, H. L.; VINCENT, J. L. (Eds.). Proceedings of 29th Conference of the International Group for the Psychology of Mathematics Education. Melbourne: PME, 2005. v. 4. p. $17-24$.

OLIVEIRA, L. M. C. P. Raciocínio proporcional em um problema envolvendo relações de proporcionalidade: aspectos evidenciados na COP-PAEM. In: ENCONTRO NACIONAL DE EDUCAÇÃO MATEMÁTICA, 12., 2016, São Paulo. Anais... São Paulo: SBEM, 2016.

OLIVEIRA, L. M. C. P. Aprendizagens no Empreendimento Estudo do Raciocínio Proporcional. 2014. 206 f. Dissertação (Mestrado em Ensino de Ciências e Educação Matemática) - Universidade Estadual de Londrina, Londrina, 2014.

ONTARIO MINISTRY OF EDUCATION. Paying Attention to Proportional Reasoning: Support Document for Paying Attention to Mathematical Education. Toronto: Queen's Printer for Ontario, 2012.

PARANÁ. Secretaria de Estado da Educação do Paraná. Secretaria de Educação Básica. Diretrizes Curriculares da Educação Básica: matemática. Curitiba: SEED, 2008.

REZENDE, M. F.; COUTINHO, L.; TORTOLA, E. Depois de brincar, vamos guardar! Uma atividade de modelagem matemática na Educação Infantil. In: ENCONTRO NACIONAL DE EDUCAÇÃO MATEMÁTICA, 13., 2019, Cuiabá. Anais... Cuiabá: SBEM, 2019.

REZENDE, M. F.; FADIN, C.; TORTOLA, E. Investigando padrões em atividades de modelagem matemática na Educação Infantil. In: CONFERÊNCIA NACIONAL SOBRE MODELAGEM NA EDUCAÇÃO MATEMÁTICA, 11., 2019, Belo Horizonte. Anais... Belo Horizonte: UFMG, 2019.

SILVA, P. F. Modelagem Matemática na Educação Infantil: uma estratégia de ensino com crianças da faixa etária de 4 a 5 anos. 172 f. Dissertação (Mestrado em Ensino de Ciências Exatas) - Centro Universitário Univates, Lajeado, 2013.

SILVA, V.; KLÜBER, T. E. Modelagem matemática nos anos iniciais do ensino fundamental: uma investigação imperativa. Revista Eletrônica de Educação, São Carlos, v. 6, n. 2, p. 228-249, nov. 2012.

SPINILLO, A. G. Raciocínio proporcional em crianças: considerações acerca de alternativas educacionais. Revista Pro-Posições, Campinas, v. 5, n. 1, p.109-114, 1994.

TORTOLA, E. Configurações de modelagem matemática nos anos iniciais do Ensino Fundamental. 2016. 306 f. Tese (Doutorado em Ensino de Ciências e Educação Matemática) - Universidade Estadual de Londrina, Londrina, 2016.

TORTOLA, E. Os usos da linguagem em atividades de Modelagem Matemática nos anos iniciais do Ensino Fundamental. 168 f. Dissertação (Mestrado em Ensino de Ciências e Educação Matemática) - Universidade Estadual de Londrina, Londrina, 2012. 
TORTOLA, E.; ALMEIDA, L. M. W. Reflexões a respeito do uso da modelagem matemática em aulas nos anos iniciais do Ensino Fundamental. Revista Brasileira de Estudos Pedagógicos, Brasília, v. 94, n. 237, p. 619-642, maio/ago. 2013.

TORTOLA, E.; ALMEIDA, L. M. W. Um olhar sobre os usos da linguagem por alunos dos anos iniciais do ensino fundamental em atividades de modelagem matemática. Revista Paranaense de Educação Matemática, Campo Mourão, v. 5 , p. $83-105,2016$.

VAN DE WALLE, J. A. Matemática no Ensino Fundamental: formação de professores e aplicação em sala de aula. 6. ed. Porto Alegre: Penso Editora, 2009.

ZAMPIROLLI, A. C.; KATO, L. A. Ensino de matemática na Educação Infantil: uma experiência por meio da modelagem matemática. In: CONFERÊNCIA NACIONAL SOBRE MODELAGEM NA EDUCAÇÃO MATEMÁTICA, 11., 2019, Belo Horizonte. Anais... Belo Horizonte: UFMG, 2019.

ZAMPIROLLI, A. C. A modelagem matemática como favorecedora da aprendizagem na Educação Infantil. 2020. 167 f. Dissertação (Mestrado em Educação para a Ciência e a Matemática) - Universidade Estadual de Maringá, Maringá, 2020.

RECEBID0 EM: 06 jul. 2020

CONCLUÍDO EM: 02 out. 2020 
